\title{
Effect of anxiolytic and hypnotic drug prescriptions on mortality hazards: retrospective cohort study
}

\author{
(9) (1) OPEN ACCESS
}

\author{
Scott Weich professor of psychiatry ${ }^{1}$, Hannah Louise Pearce prescribing and public health analyst ${ }^{2}$, \\ Peter Croft professor of primary care epidemiology ${ }^{3}$, Swaran Singh professor of social and community \\ psychiatry ${ }^{1}$, Ilana Crome professor of addiction psychiatry ${ }^{4}$, James Bashford lecturer in primary \\ care research $^{2}$, Martin Frisher reader in health services research ${ }^{2}$
}

${ }^{1}$ Division of Mental Health and Wellbeing, Warwick Medical School, University of Warwick, Coventry, West Midlands CV4 7AL, UK; ${ }^{2}$ School of Pharmacy, Keele University, Keele, Staffordshire, UK; ${ }^{3}$ Institute of Primary Care and Health Sciences, Keele University, Keele, Staffordshire, UK; ${ }^{4}$ Academic Psychiatry Unit, St George's Hospital, South Staffordshire and Shropshire Healthcare NHS Foundation Trust, Stafford, Staffordshire, UK

\begin{abstract}
Objective To test the hypothesis that people taking anxiolytic and hypnotic drugs are at increased risk of premature mortality, using primary care prescription records and after adjusting for a wide range of potential confounders.

Design Retrospective cohort study.

Setting 273 UK primary care practices contributing data to the General Practice Research Database.

Participants 34727 patients aged 16 years and older first prescribed anxiolytic or hypnotic drugs, or both, between 1998 and 2001, and 69 418 patients with no prescriptions for such drugs (controls) matched by age, sex, and practice. Patients were followed-up for a mean of 7.6 years (range 0.1-13.4 years).
\end{abstract}

Main outcome All cause mortality ascertained from practice records.

Results Physical and psychiatric comorbidities and prescribing of non-study drugs were significantly more prevalent among those prescribed study drugs than among controls. The age adjusted hazard ratio for mortality during the whole follow-up period for use of any study drug in the first year after recruitment was 3.46 (95\% confidence interval 3.34 to 3.59 ) and 3.32 (3.19 to 3.45) after adjusting for other potential confounders. Dose-response associations were found for all three classes of study drugs (benzodiazepines, Z drugs (zaleplon, zolpidem, and zopiclone), and other drugs). After excluding deaths in the first year, there were approximately four excess deaths linked to drug use per 100 people followed for an average of 7.6 years after their first prescription.

Conclusions In this large cohort of patients attending UK primary care, anxiolytic and hypnotic drugs were associated with significantly increased risk of mortality over a seven year period, after adjusting for a range of potential confounders. As with all observational findings, however, these results are prone to bias arising from unmeasured and residual confounding.

\section{Introduction}

Prescribing of hypnotic and anxiolytic drugs is common ${ }^{1}$ and increasing in places. ${ }^{2}$ In 2011-12 more than 16 million prescriptions for these drugs $\mathrm{s}^{3}$ were written in general practice in England at a cost of over $£ 60 \mathrm{~m}(\$ 100 \mathrm{~m} ; € 73 \mathrm{~m})$ per annum. Benzodiazepines currently account for $62 \%$ and $\mathrm{Z}$ drugs (zaleplon, zolpidem, and zopiclone) $32 \%$ of total prescriptions for hypnotics and anxiolytics in primary care in England. ${ }^{24}$

Evidence of adverse effects ${ }^{5}$ including increased risk of dementia $^{6-8}$ and other psychomotor impairments (daytime fatigue, ataxia, falls, and road traffic incidents), ${ }^{9-14}$ cancer, ${ }^{15-17}$ pneumonia, and other infection $\mathrm{s}^{18}$ has increased concerns of an association with premature mortality. Until recently evidence for this was based on a small number of studies, which varied in setting, sample (especially age distribution), length of follow-up, source of drug usage data, ${ }^{19-21}$ type of drug, and the extent of control for confounding (especially from physical and psychiatric comorbidity, co-prescribing, socioeconomic status, smoking, and drug and alcohol misuse). ${ }^{722}{ }^{23}$ Although two studies in older populations did not report a statistically significant association between benzodiazepine use and mortality after adjusting for confounders, ${ }^{24}{ }^{25}$ four others (in younger samples) found evidence of significantly increased mortality. ${ }^{190222326}$ A study in people with schizophrenia reported associations with suicide and with all cause mortality. ${ }^{27}$ Adjusted hazard ratios have varied substantially, ranging from $1.14^{21}$ to $4.56 .{ }^{1623}{ }^{27} \mathrm{~A}$ recent study ${ }^{23}$ found that the mortality risk extended to those with low levels of use, was greater in younger people, and that heavy use of hypnotics increased the 
risk of developing cancer. ${ }^{23}$ Questions remain about effect size, interactions with age, ${ }^{2022} 24$ and confounding (particularly by anxiety and other psychiatric disorders).

We tested the hypothesis that people taking anxiolytic or hypnotic drugs, or both, are at significantly increased risk of death compared with non-users and to estimate the size of this association after adjusting for a wide range of potential confounders using prescribing data from UK primary care.

\section{Methods}

We undertook a retrospective, matched cohort study using the General Practice Research Database (GPRD). GPRD (incorporated into the Clinical Practice Research Datalink in 2012) was created in 1987 and is the largest anonymised, longitudinal primary care database in the world, with around 70 million patient years of high quality validated data from 630 practices. In 2011 over 11 million patient records were in the GPRD (five million active), equivalent to $8.3 \%$ of the UK population. ${ }^{28}$ The database contains records from clinical consultations with general practitioners, prescriptions, secondary care referrals, and hospital admissions.

This project was awarded a licence as part of a scheme operated by the UK Medical Research Council and Medicines and Healthcare products Regulatory Agency to provide data access on up to 100000 patients. Data were based on records from 273 primary care practices in England, Scotland, Wales, and Northern Ireland.

\section{Participants}

Eligible participants were patients aged 16 years and older, permanently registered with a practice contributing data to the GPRD, and with at least 12 months of up to standard records (as per GPRD data quality standards). We identified patients who had received study drugs by incident (first ever) prescription of an anxiolytic or hypnotic drug (see chapters 4.1.1 and 4.1.2 of the British National Formulary ${ }^{29}$ ), excluding barbiturates, during the recruitment window from January 1998 to December 2001. We only included patients who received at least two prescriptions for a given study drug during the recruitment period. This was done to minimise misclassification of use among people who received but did not fill the prescription or take the drug. ${ }^{30}$ We reasoned that a second (that is, repeat) prescription indicated that the first had been filled and taken. Examination of a subsample of GPRD records (not reported here) found that $40.3 \%$ of people in receipt of a lifetime prescription for an anxiolytic or hypnotic drug only ever received a single prescription for that drug. No prescriptions for any study drugs were recorded for participants (whether users or non-users) for the duration of their practice record before recruitment into the study. Mean duration of registration with study practices before recruitment was 15.6 years (SD 14.0).

To improve efficiency and reduce the number of required patients who were prescribed the study drugs, we matched each patient prescribed any study drugs to two controls from among those with no prescription for any study drugs, on age (three years either way), sex, and practice. The 2:1 recruitment strategy was also determined by the 100000 limit on the total sample size under the terms of our data license. Matching occurred (and follow-up started) at the time of the first prescription for a study drug. The period during which the study outcome (death) was ascertained therefore began at exactly the same time for both patients prescribed the study drugs and (matched) controls. Both groups of patients were followed until the earliest of death, censorship (no longer registered with practice), or truncation (end of the observation period on 31 October 2011). Study outcome was all cause mortality as recorded in the practice record. The observation period for the ascertainment of covariates was the entire interval for which data are available for a patient between the time their record starts (before recruitment) and either death, censorship, or truncation. To reduce the likelihood of bias arising from the prescription of study drugs to those who were terminally ill and nearing the end of life, we restricted the study sample further in our final model to patients who survived for longer than 12 months after recruitment.

\section{Ascertainment of study drug use}

We ascertained the receipt of hypnotic and anxiolytic drugs from electronic prescribing records. Use was initially quantified in terms of defined daily doses from study entry point to the end of each patient's observation period. The defined daily dose is the assumed average maintenance dose per day for a drug used for its main indication in adults (considered to be someone of $70 \mathrm{~kg}$ body weight). ${ }^{32}$ The defined daily dose, a measure of equivalence that permits pooling of usage data across different drugs used for the same indications and values, are available from the WHO Collaborating Centre for Drug Statistics Methodology (www.whocc.no/atc_ddd_index). The defined daily doses in the exposed group were recoded as a categorical variable: $1-30,31-60,61-90$, and $\geq 91$, corresponding to prescriptions of one, two, three, or more than three months' duration. We classified study drugs as benzodiazepines, $Z$ drugs (zaleplon, zolpidem, and zopiclone), and other. Patients who were prescribed study drugs were further dichotomised according to whether or not the study drug continued to be prescribed after the first 12 months of observation.

\section{Covariates and potential confounders}

Statistical adjustment was undertaken for potential confounders. Controlling for confounding by indication (that is, possible reasons for being prescribed a study drug) is especially important. Potential confounders included sex, age at study entry, sleep disorders, anxiety disorders, other psychiatric disorders, medical morbidity, and prescriptions for non-study drugs. Smoking and alcohol use were recorded within the dataset as current, former, or never. As a means of controlling partially for differences in socioeconomic status, we matched patients who were or were not prescribed study drugs by practice.

Medical morbidity was ascertained using Read codes for arthritis and musculoskeletal problems, asthma, cancer, chronic obstructive pulmonary disease, diabetes, gastrointestinal disorders, epilepsy, hypertension, ischaemic heart disease, stroke, and sleep disorders (www.connectingforhealth.nhs.uk/ systemsandservices/data/uktc/readcodes). We subdivided psychiatric codes into anxiety disorders (the main indication for anxiolytic prescribing) and all other psychiatric disorders.

\section{Data analysis}

Using Cox proportional hazards models, we estimated the hazard ratios for death after recruitment into the study cohort (defined as the first prescription of a study drug). Exploratory analyses showed that the hazard function (for the association between study drugs and mortality) varied with age (results available from authors); we therefore stratified regression analyses by this variable.

In the first model we included prescriptions for all study drugs during the observation period (following recruitment) and 
included all deaths, regardless of timing. In the second model (to minimise confounding of use by survival) we restricted the exposed patient sample to those who were prescribed study drugs only in the first year after recruitment. All deaths were included, regardless of timing. In the third and final model, we further restricted both patient groups to those who survived for more than 12 months (and therefore after study drug prescription had ceased in the group using the study drugs).

We assessed the extent of co-prescribing of study drugs. Since $75.9 \%(n=26347)$ of patients who used study drugs had received at least one prescription for a benzodiazepine and $31.5 \%(n=10$ 877 ) had received more than one class of study drug, we opted to pool estimates of association with mortality across groups in our primary analyses. We undertook subgroup analyses in which the group prescribed the study drugs was restricted to those who received benzodiazepines only, $\mathrm{Z}$ drugs only, or other study drugs only, in the first year after recruitment. MF and HP undertook all analyses by using SPSS version 19.0.

\section{Results}

Data were obtained on 34804 patients who were prescribed the study drugs and 69585 patients (matched) who were not (controls). Seventy seven patients who were prescribed the study drugs were excluded (with 154 matched controls) owing to insufficient data to allow defined daily doses to be calculated. We also excluded 13 "unexposed" patients who had been prescribed melatonin during the observation period. The final sample for study models comprised 104145 patients, of whom 34727 were prescribed the study drugs and 69418 were controls. Censorship (excluding death) was observed for $26.7 \%$ $(n=9314)$ of the patients who were prescribed the study drugs and $31.2 \%(n=21644)$ of controls (table $1 \Downarrow)$.

Benzodiazepines $(63.7 \%$ ( $n=22116)$ of patients prescribed the study drugs) were more common as the index drug class than $\mathrm{Z}$ drugs $(23.0 \%)(\mathrm{n}=7971)$ or other study drugs $(13.4 \%)$ $(\mathrm{n}=4640)$. Co-prescribing was common (table $2 \Downarrow)$. In total, $76.3 \%$ ( $\mathrm{n}=26436)$ of patients using study drugs received a prescription for a benzodiazepine, $38.8 \%(n=13444)$ a prescription for a $\mathrm{Z}$ drug, and $33.5 \%(\mathrm{n}=7444)$ a prescription for one or more of the other study drugs. The most commonly prescribed study drugs were diazepam $(47.9 \%$ of those prescribed the study drugs, $\mathrm{n}=16638)$, temazepam $(35.1 \%, \mathrm{n}=12$ $208)$, and zopiclone $(34.1 \%, \mathrm{n}=11764)$. Among the group prescribed the study drugs, $24.2 \%(\mathrm{n}=8404)$ were only prescribed diazepam, $14.8 \%(\mathrm{n}=5140)$ only temazepam, and $12.2 \%(n=4237)$ only zopiclone.

Table $3 \Downarrow$ shows the characteristics of the study sample. Patients who were prescribed study drugs were more likely than controls to be current smokers and to have higher rates of all forms of physical morbidity, most notably cancer and respiratory disorders. The group prescribed study drugs also had higher rates of sleep $(28.1 \%(\mathrm{n}=9741) v 5.8 \%(\mathrm{n}=4009))$, anxiety $(44.1 \%(\mathrm{n}=15299) v 11.3 \%(\mathrm{n}=7849)$, and other psychiatric disorders $(56.9 \%(\mathrm{n}=19770) v 21.7 \%(\mathrm{n}=15026))$ than controls, and received more prescriptions for non-study drugs.

We found statistically significant associations with mortality at all levels of study drug use. Our initial model classified use irrespective of when this occurred, and included all deaths regardless of when these occurred during the observation period (table $4 \Downarrow$ ). The hazard ratio for mortality in the group with the highest use of study drugs was lower than that in all three groups with fewer defined daily doses, suggesting that use was confounded by survival. We also noted reverse confounding on adjusting for study covariates.
In the second model (table $5 \Downarrow$ ), the exposed group was restricted to those who received no prescriptions for the study drugs after their first year of observation. The age adjusted hazard ratio for mortality for any use of study drug was 3.46 (95\% confidence interval 3.34 to 3.59 ), decreasing slightly to 3.32 (3.19 to 3.45 ) after adjusting for potential confounders. A clear dose-response association was found, with an adjusted hazard ratio for mortality of 4.51 ( 4.22 to 4.82 ) among those who received more than 90 defined daily doses of any study drug in the first year of follow-up. Associations with mortality, and dose-response effects, were found for each of the three separate classes of study drug. Hazard ratios were largest for benzodiazepines and smallest for other study drugs (table 5).

We further excluded patients in both groups with less than one year of follow-up (model 3, table $6 \Downarrow$ ). Those who survived the first year but did not receive prescriptions for the study drugs beyond the first year of observation are the subgroup analysed in table 6. They had lower rates of physical and mental health problems on all 14 indicators of comorbidity than those who were prescribed study drugs beyond the first year, including cancer $(22.9 \%(\mathrm{n}=5050) v 18.6 \%(\mathrm{n}=1599))$, chronic obstructive pulmonary disease $(15.7 \%(\mathrm{n}=3449) v 13.5 \%(\mathrm{n}=1158))$, and ischaemic heart disease $(22.5 \%(\mathrm{n}=4955) v 19.6 \%(\mathrm{n}=1683))$. Those only prescribed study drugs in year 1 also differed slightly from those who took study drugs beyond the first year on mean age at study entry (52.6 years (SD 18.9) v 54.3 years (SD 18.6), $\mathrm{P}<0.001)$ and age at death (77.2 years (SD 13.8) $v 76.8$ years (SD 14.3), $\mathrm{P}=0.38$ ). Patients who were only prescribed study drugs in year 1 were less likely to die than those who continued to take drugs $(18.8 \%(\mathrm{n}=1610) v 22.0 \%(\mathrm{n}=4852))$ but more likely to be censored for other reasons $(33.5 \%(\mathrm{n}=3028) v 22.3 \%$ $(n=4906)$ ).

Patterns of association remained in this third model, although effect sizes were reduced (adjusted hazard ratio for $>90$ defined daily doses was reduced to 2.63 (95\% confidence interval 2.34 to 2.95 ), table 6 ). The same patterns of association were found across all three classes of study drugs, with hazard ratios for benzodiazepines being the largest. The adjusted hazard ratio for use of any drug in model 2 (table 5), which included early deaths during drug use, was 3.32 (95\% confidence interval 3.19 to 3.45 ), compared with an adjusted hazard ratio for any drug use in model 3 , limited to deaths after prescriptions for the study drugs had finished, of 1.75 (1.65 to 1.85 , table 6).

\section{Discussion}

We found evidence of an association between prescription of anxiolytic and hypnotic drugs and mortality over an average follow-up period of 7.6 years among more than 100000 age and general practice matched adults. In patients who were prescribed these drugs, there was an estimated overall statistically significant doubling of the hazard of death (hazard ratio 2.08), after adjusting for a wide range of potential confounders, including physical and psychiatric comorbidities, sleep disorders, and other drugs. This association remained significant and followed a dose-response pattern after restricting analyses to those with at least 12 months of follow-up and to those who were only prescribed the study drugs in the first year after recruitment (hazard ratio 1.75). Crude cumulative mortality in those given drugs was 26.46 per 100 people over the full follow-up period compared with 16.82 per 100 controls. After excluding deaths in the first year, there were approximately four excess deaths linked to drug use per 100 people followed for an average of 7.6 years after their first prescription. 
While overall effect sizes were broadly in keeping with most previous findings, our estimates of association were lower than that reported by one study, ${ }^{23}$ which reported an adjusted hazard ratio of 4.56 over 2.5 years. This may reflect differences in the length of follow-up, as both studies reported declining associations with mortality over time.

\section{Strengths and limitations of this study}

Use of data from the UK General Practice Research Database was an obvious strength, given the size and representativeness of the sample, and the quality, completeness, and duration of the follow-up data. Data on drug use were based on documented prescriptions rather than self reported receipt or use of drugs. We had detailed information on a wide range of potential confounders, going back several years. In particular, we were able to control for a large number of physical and psychiatric morbidities as well as prescriptions of other drugs. This is especially important given the possibility of confounding by indication (that is, study drugs may be given more often to those who are seriously ill and who may not be able to sleep because of pain or other consequences of long term or life threatening illnesses). In contrast with a recent report, ${ }^{23}$ we were able to adjust for anxiety disorders as well as all other psychiatric disorders. We were also able to identify and control for recorded instances of sleep problems (including those secondary to physical and psychiatric disorders).

Our recruitment strategy and ascertainment of drug use were further strengths. We minimised misclassification by excluding people who had received only one prescription, since some people never fill prescriptions or take the drugs. Using defined daily doses to quantify cumulative use of study drugs allowed us to combine the effects of different drugs in a way that is not possible by counting prescriptions or pills. ${ }^{23}$ In further contrast with previous research, ${ }^{23}$ we chose to classify study drugs by class rather than by indication for the purposes of recruitment; for example, we included all benzodiazepines, not just those recorded as having been prescribed for insomnia. We would argue that this resulted in a more accurate estimation of use of these drugs, as well as ensuring that our results are generalisable to all of those who receive anxiolytic and hypnotic drugs in primary care. Our models were adjusted for all main indications for these drugs. Although pooling of study drugs may have overlooked variation in associations with mortality across classes, subgroup analyses indicated statistically significant associations (and dose-response effects) between mortality and all three classes of study drug. The largest hazard ratios were found for benzodiazepines.

Despite using prescribing records, we may have underestimated use of study drugs. Patients with more serious psychiatric disorders may be cared for by secondary care services rather than solely in primary care. Although in most cases responsibility for longer term (repeat) prescribing is usually delegated to general practice, it is possible that prescribing for these patients may be under-recorded in the General Practice Research Database. Likewise, we had no information on the use of study drugs that were obtained illicitly, although this was likely to have been modest compared with use of prescribed drugs. It is highly unlikely that study drugs were used before recruitment among the patients eventually prescribed the drugs or controls, given that the patients were registered with the study practices for 15 years on average. This was not so in a previous study, ${ }^{23}$ in which around one fifth of the exposed group had received a prescription for a study drug before recruitment.
The length of follow-up was also a strength, particularly for the generalisability of the findings. However, higher effect estimates obtained when we restricted our sample of exposed patients to those with no further prescriptions for the study drugs after the first 12 months suggests that results from our initial model, which included patients who continued to receive prescriptions for the study drugs throughout the observation period, may have been biased towards the null by the confounding of use and survival. Results of models in which use was restricted to the first year after recruitment and deaths restricted to those occurring after that first year suggest that much of the excess mortality risk arises early in the period of drug use but remains statistically significant even after discontinuing study drugs. We were not, however, able to explore temporal risk trajectories in detail. It was possible that patients who discontinued drugs within the first year did so because they were particularly unwell (and more morbid than those who continued to take these drugs). However, our findings show that the opposite was true, which strengthens the validity of our estimates of excess mortality in this group compared with the control group. Although those for whom prescriptions for study drugs stopped after the first year were more likely to be censored for reasons other than death, there is no reason to believe that this inflated the association between study drugs and mortality.

Non-randomised outcome studies are especially prone to confounding, including confounding by indication. One option for dealing with confounding by indication is using a comparator group more closely aligned with the exposed group-for example, patients who were starting other types of drugs. However, in the absence of previous evidence that comparator drugs were free of other indication effects, this would again have not ruled out this bias, even though it may have accounted for bias related to the comparison with non-users. Instead, we chose to deal with this in four ways: by taking account of a large number of potential confounders, by comparing effects across different groups of study drugs, by conducting subgroup analyses that limited exposure to year 1 and excluded all deaths during that first year in patients who both used and did not use the study drugs (on the grounds that confounding by indication will have the largest effect in year 1), and by adjusting our estimates of association for comorbidities occurring across the entire follow-up period. Nevertheless, although we controlled for many potential factors that were associated with study drug use and mortality and eliminated confounding of use and survival, it is impossible to exclude confounding arising from unmeasured factors or measurement error. ${ }^{33-35}$ While effects on estimates of association can be substantial, ${ }^{33}$ such bias is greatest for unmeasured confounders and those that are uncorrelated with other confounders but correlated with the study exposure. ${ }^{34}$ Bias tends to be greatest in studies that control for relatively few measured confounders. ${ }^{34}$

Although bias due to confounding was likely to have occurred, the impact was offset by the large number of covariates included in our analyses. One important unmeasured confounder is socioeconomic status, since records in the General Practice Research Database do not include detailed information on occupation, education, housing tenure, income, or employment. However, this variable was partially controlled for by matching by practice. Residual confounding, arising from a mixture of misclassification and indication, was also likely to have occurred in the recording of clinical diagnoses, and through our inability to quantify the severity of illness. Again, this is likely to have been offset to an extent by controlling for a wide range of comorbidities. Adjustment for a large number of measured confounders failed to negate our finding of an association 
between drug use and mortality but has resulted in appropriately more conservative estimates of the size of this association. ${ }^{23}$

Cohort studies are also prone to immortal time bias, which arises if the period participants are considered at risk differs between comparator groups. ${ }^{36}$ Although mortality was counted from the time of the first prescription for all patients, the time until second prescription would be "immortal" for patients who used the study drugs and who had to survive to get a second prescription to be in the study. This would not have applied to controls. However, excluding deaths among those who did not survive to receive a second prescription would have underestimated mortality in patients who used the study drugs. Any bias in the mortality comparison would therefore have been towards the null. Furthermore, this would not have biased the subgroup analysis that excluded early deaths, since deaths were ascertained only after the first year of follow-up for patients who both did and did not use the study drugs.

We considered the possibility of collider bias, a form of selection bias that may occur when two variables are not associated but share a common antecedent or outcome. Adjusting for such a factor can result in a spurious association. ${ }^{37}$ It is possible, for example, that study drug use and mortality are both associated with (for example) physical illness but themselves are not related. Since adjusting for comorbidities reduced estimates of association between study drugs and mortality, we suggest that these variables were likely to have been acting as classic confounders rather than sources of selection bias.

We did not have access to data on cause of death and therefore were unable to explore associations between prescription of study drugs and specific forms of morbidity such as pneumonia. Neither did we explore interactions between individual forms of morbidity and vulnerability to specific drug classes. In the light of consistent evidence of associations with mortality, such investigations are needed and will be the subject of future studies.

\section{Conclusions}

These findings are consistent with previous evidence of a statistically and clinically significant association between anxiolytic and hypnotic drugs and mortality. Using prescribing data from a large primary care database and after adjusting for a wide range of potential confounders, prescriptions for these drugs were associated with significantly increased risks of mortality over an average follow-up period of 7.6 years. This association followed a dose-response pattern for all three classes of study drug and extended beyond the time of use. However, as with all observational studies, these findings remain prone to many forms of bias. While we have largely excluded immortal time bias and selection bias, we are unable to exclude the possibility that the results were due to confounding by indication or to residual confounding by unmeasured or incompletely measured factors, such as socioeconomic status. This applies especially to deaths in the first year of observation. These results add to evidence of an association with mortality, but must be treated with caution.

This study is based on data from the Full Feature General Practice Research Database obtained under licence from the UK Medicines and Healthcare Products Regulatory Agency (MHRA). However, the interpretation and conclusions contained in this study are those of the authors alone. Access to the General Practice Research Database was funded through the Medical Research Council's licence agreement with MHRA. We thank Tarita Murray-Thomas at the MHRA for producing the dataset, and all contributing general practitioners and their patients. $P C$ is a senior investigator for the National Institute for Health Research.

Contributors: SW, MF, SS, and IC had the original idea for this study. SW and MF were responsible for study hypotheses, design, data specification, analysis, and drafting of the manuscript. MF and HP undertook the analyses, and results were interpreted by all authors. PC advised on data analysis and interpretation of the study findings. MF had full access to all the data in the study and takes responsibility for the integrity of the data and the accuracy of the data analysis. All authors contributed to the drafting of the manuscript. SW is the guarantor.

Funding: This study received no specific funding. This project was awarded a licence as part of a scheme operated by the UK Medical Research Council and Medicines and Healthcare products Regulatory Agency to provide data access on up to 100000 patients. Data were based on records from 273 primary care practices in England, Scotland, Wales, and Northern Ireland. The providers of this license did not have any involvement in the conduct of the research and were not consulted in the drafting of the manuscript.

Competing interests: All authors have completed the ICMJE uniform disclosure form at www.icmje.org/coi_disclosure.pdf and declare: no support from any organisation for the submitted work; no financial relationships with any organisations that might have an interest in the submitted work in the previous three years; no other relationships or activities that could appear to have influenced the submitted work.

Ethical approval: This project was approved by the Warwick Medical School Biomedical Research Ethics Committee (reference 192-03-2012). Data sharing: No additional data available. The study data remain the property of the Clinical Practice Research Datalink (formerly General Practice Research Database) and was provided to the authors under license.

Transparency: SW (the manuscript's guarantor) affirms that the manuscript is an honest, accurate, and transparent account of the study being reported; that no important aspects of the study have been omitted; and that any discrepancies from the study as planned (and, if relevant, registered) have been explained.

1 Tsimtsiou Z, Ashworth M, Jones R. Variations in anxiolytic and hypnotic prescribing by GPs: a cross-sectional analysis using data from the UK Quality and Outcomes Framework. Br J Gen Pract 2009;59:e191-8.

2 NHS Prescription Services. Central nervous system national charts. NHS Business Services Authority, 2012.

3 Royal College of General Practitioners and Royal College of Psychiatrists. Addiction to medicines consensus statement 2013. www.rcgp.org.uk/news/2013/january/addiction-tomedicines-consensus-statement.aspx.

4 Huedo-Medina TB, Kirsch I, Middlemass J, Klonizakis M, Siriwardena AN. Effectiveness of non-benzodiazepine hypnotics in treatment of adult insomnia: meta-analysis of data submitted to the Food and Drug Administration. BMJ 2012;345:e8343.

5 Glass J, Lanctôt KL, Herrmann N, Sproule BA, Busto UE. Sedative hypnotics in older people with insomnia: meta-analysis of risks and benefits. BMJ 2005;331:1169.

Billioti de Gage S, Begaud B, Bazin F, Verdoux H, Dartigues J-F, Peres K, et al. Benzodiazepine use and risk of dementia: prospective population based study. BMJ 2012;345:e6231.

7 Gallacher J, Elwood P, Pickering J, Bayer A, Fish M, Ben-Shlomo Y. Benzodiazepine use and risk of dementia: evidence from the Caerphilly Prospective Study (CaPS). J Epidemiol Community Health 2012;66:869-73.

8 Wu CS, Ting TT, Wang SC, Chang IS, Lin KM. Effect of benzodiazepine discontinuation on dementia risk. Am J Geriatr Psychiatry 2011;19:151-9.

9 Kripke DF. Chronic hypnotic use: deadly risks, doubtful benefit. Sleep Med Rev 2000;4:5-20.

10 Paterniti S, Dufouil C, Alpérovitch A. Long-term benzodiazepine use and cognitive decline in the elderly: the Epidemiology of Vascular Aging Study. J Clin Psychopharmacol 2002;22:285-93.

11 Barker MJ, Greenwood KM, Jackson M, Crowe SF. Cognitive effects of long-term benzodiazepine use: a meta-analysis. CNS Drugs 2004;18:37-48.

12 Kripke DF. Greater incidence of depression with hypnotic use than with placebo. BMC Psychiatry 2007;7:42.

13 Neutel $\mathrm{Cl}$. Risk of traffic accident injury after a prescription for a benzodiazepine. Ann Epidemiol 1995:5:239-44.

14 Berry SD, Lee Y, Cai S, Dore DD. Nonbenzodiazepine sleep medication use and hip fractures in nursing home residents. JAMA Intern Med 2013:1-8.

15 Kripke DF. Possibility that certain hypnotics might cause cancer in skin. J Sleep Res 2008;17:245-50.

16 Mallon L, Broman JE, Hetta J. Is usage of hypnotics associated with mortality? Sleep Med 2009;10:279-86.

$17 \mathrm{Kao} \mathrm{CH}$, Sun LM, Su KP, Chang SN, Sung FC, Muo CH, et al. Benzodiazepine use possibly increases cancer risk: a population-based retrospective cohort study in Taiwan. $J$ Clin Psychiatry 2012;73:e555-60. 


\section{What is already known on this topic}

Anxiolytic and hypnotic drugs are addictive and associated with cognitive and psychomotor impairments, falls, and unintentional injuries It has long been suspected that these drugs are associated with premature mortality

Studies of the association between anxiolytic and hypnotic drugs and mortality have reported widely varying effect sizes, reflecting variation in methods

\section{What this study adds}

In this large cohort of patients attending UK primary care, anxiolytic and hypnotic drugs were associated with a significantly increased risk of mortality over a seven year period

After excluding deaths in the first year, there were about four excess deaths linked to drug use per 100 people followed for an average of 7.6 years after their first prescription

The risk followed a dose-response pattern and was found for all three classes of study drugs and did not seem to be entirely due to confounding by physical or psychiatric comorbidity or prescribing of other drugs

This study controlled for a wide range of potential confounders including the major sources of confounding by indication

18 Obiora E, Hubbard R, Sanders RD, Myles PR. The impact of benzodiazepines on occurrence of pneumonia and mortality from pneumonia: a nested case-control and survival analysis in a population-based cohort. Thorax 2013;68:163-70.

19 Hausken AM, Skurtveit S, Tverdal A. Use of anxiolytic or hypnotic drugs and total mortality in a general middle-aged population. Pharmacoepidemiol Drug Saf 2007;16:913-8.

20 Belleville G. Mortality hazard associated with anxiolytic and hypnotic drug use in the national population health survey. Can J Psychiatry 2010;55:558-67.

21 Hartz A, Ross JJ. Cohort study of the association of hypnotic use with mortality in postmenopausal women. BMJ Open 2012:e001413.

22 Charlson F, Degenhardt L, McLaren J, Hall W, Lynskey M. A systematic review of research examining benzodiazepine-related mortality. Pharmacoepidemiol Drug Saf 2009;18:93-103.

23 Kripke DF, Langer RD, Kline LE. Hypnotics' association with mortality or cancer: a matched cohort study. BMJ Open 2012:2:e000850.

24 Gisev N, Hartikainen S, Chen TF, Korhonen M, Bell JS. Mortality associated with benzodiazepines and benzodiazepine-related drugs among community-dwelling older people in Finland: a population-based retrospective cohort study. Can J Psychiatry 2011;56:377-81.

25 Vinkers DJ, Gussekloo J, Van der Mast RC, Zitman FG, Westendorp RGJ. Benzodiazepine use and risk of mortality in individuals aged 85 years or older. JAMA 2003;290:2942-3.

26 Kripke DF, Klauber MR, Wingard DL, Fell RL, Assmus JD, Garfinkel L. Mortality hazard associated with prescription hypnotics. Biol Psychiatry 1998;43:687-93.

27 Tiihonen J, Suokas JT, Suvisaari JM, Haukka J, Korhonen P. Polypharmacy with antipsychotics, antidepressants, or benzodiazepines and mortality in schizophrenia. Arch Gen Psychiatry 2012;69:476-83.

28 Khan NF, Harrison SE, Rose PW. Validity of diagnostic coding within the General Practice Research Database: a systematic review. Br J Gen Pract 2010;60:e128-36.

29 BMA and Royal Pharmaceutical Society of Great Britain. British national formulary. 63 ed. BMJ Group and RPS Publishing, 2012.

30 Solomon MD, Majumdar SR. Primary non-adherence of medications: lifting the veil on prescription-filling behaviors. J Gen Internl Med 2010;25:280-1.
31 Fischer MA, Stedman MR, Lii J, Vogeli C, Shrank WH, Brookhart MA, et al. Primary medication non-adherence: analysis of 195,930 electronic prescriptions. $J$ Gen Intern medication non-adheren

32 WHO Collaborating Centre for Drug Statistics Methodology. Guidelines for ATC classification and DDD assignment 2012. WHO Collaborating Centre for Drug Statistics Methodology, 2011.

33 Savitz DA, Baron AE. Estimating and correcting for confounder misclassification. Am J Epidemiol 1989:129:1062-71.

34 Fewell Z, Davey Smith G, Sterne JAC. The impact of residual and unmeasured confounding in epidemiologic studies: a simulation study. Am J Epidemiol 2007;166:646-55.

35 Lawlor DA, Smith GD, Bruckdorfer KR, Kundu D, Ebrahim S. Those confounded vitamins: what can we learn from the differences between observational versus randomised trial evidence? Lancet 2004;363:1724-7.

36 Lévesque LE, Hanley JA, Kezouh A, Suissa S. Problem of immortal time bias in cohort studies: example using statins for preventing progression of diabetes. BMJ 2010;340:b5087.

37 Cole SR, Platt RW, Schisterman EF, Chu H, Westreich D, Richardson D, et al. Illustrating bias due to conditioning on a collider. Int J Epidemiol 2010;39:417-20.

\section{Accepted: 18 February 2014}

\section{Cite this as: BMJ 2014;348:g1996}

This is an Open Access article distributed in accordance with the terms of the Creative Commons Attribution (CC BY 3.0) license, which permits others to distribute, remix, adapt and build upon this work, for commercial use, provided the original work is properly cited. See: http://creativecommons.org/licenses/by/3.0/. 


\section{Tables}

Table 1 | Study drugs by drug class, showing defined daily doses (DDDs) and proportion of patients ( $\mathrm{n}=34 \mathrm{727}$ ) who received a prescription for each of these during the observation period

\begin{tabular}{|c|c|c|}
\hline Drug class and type & DDDs (mg) & No (\% using drug) \\
\hline \multicolumn{3}{|l|}{ Benzodiazepines: } \\
\hline Alprazolam & 1 & $19(0.05)$ \\
\hline Chlordiazepoxide & 30 & $1788(5.15)$ \\
\hline Clobazam & 20 & $164(0.47)$ \\
\hline Clonazepam & 8 & $802(2.31)$ \\
\hline Diazepam & 10 & $16638(47.91)$ \\
\hline Flunitrazepam & 1 & $3(0.01)$ \\
\hline Flurazepam hydrochloride & 30 & $17(0.05)$ \\
\hline Loprazolam mesilate & 1 & $161(0.46)$ \\
\hline Lorazepam & 2.5 & $1472(4.24)$ \\
\hline Lormetazepam & 1 & $665(1.91)$ \\
\hline Midazolam (including all salts) & 15 & $523(1.51)$ \\
\hline Nitrazepam & 5 & $1557(4.48)$ \\
\hline Oxazepam & 50 & $597(1.72)$ \\
\hline Temazepam & 20 & $12208(35.15)$ \\
\hline Triazolam & 0.25 & $0(0)$ \\
\hline Any benzodiazepine & - & $26347(75.87)$ \\
\hline \multicolumn{3}{|l|}{ Z drugs: } \\
\hline Zaleplon & 10 & $481(1.39)$ \\
\hline Zolpidem tartrate & 10 & $2737(7.88)$ \\
\hline Zopiclone & 7.5 & $11764(33.88)$ \\
\hline Any $Z$ drug & - & $13443(38.71)$ \\
\hline \multicolumn{3}{|l|}{ Other drugs: } \\
\hline Alimemazine tartrate & 30 & $331(0.95)$ \\
\hline Buspirone hydrochloride & 30 & $916(2.64)$ \\
\hline Chloral hydrate & 1000 & $72(0.21)$ \\
\hline Clomethiazole & 1500 & $400(1.15)$ \\
\hline Clomethiazole edisilate & 1500 & $82(0.24)$ \\
\hline Cloral betaine & 1000 & $472(1.36)$ \\
\hline Dichloralphenazone & 1300 & $0(0)$ \\
\hline Diphenhydramine hydrochloride & 200 & $0(0)$ \\
\hline Hydroxyzine hydrochloride & 75 & $2475(7.13)$ \\
\hline Melatonin & 2 & $66(0.19)$ \\
\hline Meprobamate & 1200 & $12(0.03)$ \\
\hline Methyprylone & 200 & $0(0)$ \\
\hline Promethazine hydrochloride & 25 & $1184(3.41)$ \\
\hline Sodium oxybate & 7500 & $0(0)$ \\
\hline Triclofos sodium & 1000 & $6(0.02)$ \\
\hline Any other drug & - & $7445(21.44)$ \\
\hline
\end{tabular}


Table 2| Patterns of prescribing and co-prescribing of study drugs at any time during observation period

\begin{tabular}{lc} 
Prescribed drug combinations & No $(\%)$ using drug \\
\begin{tabular}{l} 
No co-prescribing: \\
\hline Benzodiazepines only
\end{tabular} & $16242(46.8)$ \\
\hline Z drugs only & $4736(13.5)$ \\
\hline Other drugs only & $2872(8.3)$ \\
\hline Co-prescribing from two classes: & $6305(18.2)$ \\
\hline Benzodiazepines and Z drugs & $2169(6.3)$ \\
\hline Benzodiazepines and other drugs & $683(2.0)$ \\
\hline Z drugs and other drugs & $1720(5.0)$ \\
\hline Co-prescribing of all drugs from all three classes: \\
\hline Benzodiazepines, Z drugs, and other drugs \\
\hline Total & $34727(100)$ \\
\hline
\end{tabular}




\begin{tabular}{|c|c|c|c|}
\hline \multirow[b]{2}{*}{ Characteristics } & \multicolumn{2}{|c|}{ Study drug use } & \multirow[b]{2}{*}{$P$ value } \\
\hline & Users $(n=34727)$ & Non-users $(n=69418)$ & \\
\hline Women & $59.0(20492)$ & $59.0(40964)$ & NS \\
\hline Mean (SD) age at study entry (years) & $55.5(19.3)$ & $55.4(19.3)$ & NS \\
\hline Mean (SD) duration of follow-up (months) & $87.6(51.1)$ & $93.5(48.5)$ & $<0.001$ \\
\hline Deaths during follow-up & $26.5(9190)$ & $16.8(11678)$ & $<0.001$ \\
\hline Mean (SD) age at death (years) & $76.2(14.1)$ & $82.1(10.9)$ & $<0.001$ \\
\hline \multicolumn{4}{|l|}{ Smoking status: } \\
\hline Not recorded & $6.6(2277)$ & $10.2(7105)$ & \multirow[t]{4}{*}{$<0.001$} \\
\hline Never smoker & $45.8(15888)$ & $53.6(37202)$ & \\
\hline Current smoker & $25.3(8784)$ & $15.0(10388)$ & \\
\hline Former smoker & $22.4(7778)$ & $21.2(14723)$ & \\
\hline \multicolumn{4}{|l|}{ Alcohol status: } \\
\hline Not recorded & $14.2(4915)$ & $18.6(12897)$ & \multirow[t]{4}{*}{$<0.001$} \\
\hline Never drinker & $18.3(6342)$ & $15.3(10617)$ & \\
\hline Current drinker & $64.1(22262)$ & $64.5(44760)$ & \\
\hline Former drinker & $3.5(1208)$ & $3.4(2352)$ & \\
\hline \multicolumn{4}{|l|}{ Prescriptions: } \\
\hline Median No (range) for study drug DDDs & $70(1-33521)$ & 0 & - \\
\hline Median No (range) of non-study drug prescriptions & $227(0-12998)$ & $83(0-6435)$ & $<0.001$ \\
\hline \multicolumn{4}{|l|}{ Medical morbidity: } \\
\hline Arthritis & $25.5(8853)$ & $20.3(14110)$ & $<0.001$ \\
\hline Musculoskeletal problems & $29.8(28621)$ & $17.6(6106)$ & $<0.001$ \\
\hline Asthma & $17.3(6003)$ & $11.2(7785)$ & $<0.001$ \\
\hline Cancer & $23.7(8233)$ & $17.9(12422)$ & $<0.001$ \\
\hline Chronic obstructive pulmonary disease & $15.3(5298)$ & $9.9(6872)$ & $<0.001$ \\
\hline Gastrointestinal disorder & $3.8(1315)$ & $2.2(1526)$ & $<0.001$ \\
\hline Ischaemic heart disease & $23.1(8033)$ & $18.1(6274)$ & $<0.001$ \\
\hline Diabetes & $13.8(4778)$ & $11.7(8135)$ & $<0.001$ \\
\hline Epilepsy & $5.1(1757)$ & $2.0(1418)$ & $<0.001$ \\
\hline Hypertension & $29.2(10141)$ & $27.3(18964)$ & $<0.001$ \\
\hline Stroke & $10.4(3622)$ & $7.3(5061)$ & $<0.001$ \\
\hline Sleep disorder & $28.1(9741)$ & $5.8(4009)$ & $<0.001$ \\
\hline Anxiety disorder & $44.1(15299)$ & $11.3(7849)$ & $<0.001$ \\
\hline Other psychiatric diagnoses & $56.9(19770)$ & $21.7(15026)$ & $<0.001$ \\
\hline
\end{tabular}

NS=not significant; DDDs=defined daily doses. 
Table 4| Hazard ratios (95\% confidence intervals) for age adjusted associations between defined daily doses (DDDs) of study drug (versus no study drugs) before and after adjusting for other potential confounders

\begin{tabular}{|c|c|c|c|c|c|}
\hline Variables & No of patients & $\begin{array}{l}\text { Age adjusted hazard ratio } \\
\qquad(95 \% \mathrm{Cl})\end{array}$ & $P$ value & $\begin{array}{l}\text { Fully adjusted* hazard ratio } \\
\qquad(95 \% \mathrm{Cl})\end{array}$ & $P$ value \\
\hline \multicolumn{6}{|c|}{ DDDs (all study drugs): } \\
\hline 0 & 69418 & 1.00 & - & 1.00 & - \\
\hline $1-30$ & 10275 & 1.89 (1.80 to 1.98$)$ & $<0.001$ & 2.07 (1.97 to 2.17 ) & $<0.001$ \\
\hline $31-60$ & 6042 & 2.38 (2.25 to 2.51 ) & $<0.001$ & 2.58 (2.44 to 2.72 ) & $<0.001$ \\
\hline $61-90$ & 3207 & 2.39 (2.23 to 2.56$)$ & $<0.001$ & 2.46 (2.29 to 2.63$)$ & $<0.001$ \\
\hline$\geq 91$ & 15203 & $1.77(1.72$ to 1.84$)$ & $<0.001$ & $1.91(1.84$ to 1.98$)$ & $<0.001$ \\
\hline Any DDDs & 34727 & $1.93(1.87$ to 1.98$)$ & $<0.001$ & 2.08 (2.02 to 2.15$)$ & $<0.001$ \\
\hline
\end{tabular}

*Adjusted for age, sex, physical health problems (arthritis, asthma, cancer, ischaemic heart disease, stroke, chronic obstructive pulmonary disease, diabetes, epilepsy, gastrointestinal disorders, hypertension, musculoskeletal disorders, anxiety disorders, sleep disorders, other (non-anxiety), psychiatric disorders, and prescriptions for non-study drugs. 
Table 5| Hazard ratios (95\% confidence interval) for age adjusted associations between defined daily doses (DDDs) of study drug (versus no study drugs) and mortality before and after adjusting for other potential confounders ${ }^{\star}$, for exposure restricted to receipt of study drugs in first year after recruitment only

\begin{tabular}{|c|c|c|c|c|c|}
\hline DDDs & No of patients & $\begin{array}{l}\text { Age adjusted hazard ratio (95\% } \\
\qquad \mathrm{Cl})\end{array}$ & $P$ value & $\begin{array}{l}\text { Fully adjusted hazard ratio } \\
\qquad(95 \% \mathrm{Cl})\end{array}$ & $P$ value \\
\hline \multicolumn{6}{|c|}{ All study drugs: } \\
\hline 0 & 69418 & 1.00 & - & 1.00 & - \\
\hline $1-30$ & 6648 & 2.47 (2.34 to 2.60$)$ & $<0.001$ & 2.55 (2.42 to 2.69 ) & $<0.001$ \\
\hline $31-60$ & 2859 & 3.87 (3.66 to 4.15$)$ & $<0.001$ & 3.78 (3.54 to 4.04$)$ & $<0.001$ \\
\hline $61-90$ & 1185 & 5.04 (4.62 to 5.50$)$ & $<0.001$ & 4.19 (3.84 to 4.58$)$ & $<0.001$ \\
\hline$\geq 91$ & 1971 & 5.59 (5.21 to 5.92$)$ & $<0.001$ & 4.51 (4.22 to 4.82$)$ & $<0.001$ \\
\hline Any DDDs & 12663 & 3.46 (3.34 to 3.59 ) & $<0.001$ & 3.32 (3.19 to 3.45$)$ & $<0.001$ \\
\hline \multicolumn{6}{|c|}{ Benzodiazepines only: } \\
\hline $1-30$ & 4625 & 2.71 (2.54 to 2.88 ) & $<0.001$ & 2.78 (2.62 to 2.96$)$ & $<0.001$ \\
\hline $31-60$ & 1414 & 5.17 (4.77 to 5.59$)$ & $<0.001$ & 4.62 (4.26 to 5.01$)$ & $<0.001$ \\
\hline $61-90$ & 549 & 6.62 (5.91 to 7.42 ) & $<0.001$ & $5.42(4.84$ to 6.08$)$ & $<0.001$ \\
\hline$\geq 91$ & 881 & 6.75 (6.18 to 7.34$)$ & $<0.001$ & 5.10 (4.67 to 5.58$)$ & $<0.001$ \\
\hline Any DDDs & 7469 & 3.89 (3.73 to 4.06$)$ & $<0.001$ & 3.68 (3.52 to 3.85 ) & $<0.001$ \\
\hline \multicolumn{6}{|c|}{ Z drugs only: } \\
\hline $1-30$ & 858 & 2.39 (2.07 to 2.77$)$ & $<0.001$ & 2.36 (2.05 to 2.74$)$ & $<0.001$ \\
\hline $31-60$ & 807 & 3.53 (3.08 to 4.04$)$ & $<0.001$ & 3.41 (2.98 to 3.91$)$ & $<0.001$ \\
\hline $61-90$ & 278 & 4.58 (3.75 to 5.59$)$ & $<0.001$ & 3.66 (2.99 to 4.48$)$ & $<0.001$ \\
\hline$\geq 91$ & 492 & $4.83(4.22$ to 5.54$)$ & $<0.001$ & 3.90 (3.39 to 4.47$)$ & $<0.001$ \\
\hline Any DDDs & 2435 & 3.50 (3.24 to 3.77 ) & $<0.001$ & 3.19 (2.95 to 3.45$)$ & $<0.001$ \\
\hline \multicolumn{6}{|c|}{ Other study drugs only: } \\
\hline $1-30$ & 976 & $1.93(1.71$ to 2.19$)$ & $<0.001$ & $1.86(1.64$ to 2.10$)$ & $<0.001$ \\
\hline $31-60$ & 378 & 2.02 (1.67 to 2.43 ) & $<0.001$ & 2.09 (1.73 to 2.51$)$ & $<0.001$ \\
\hline $61-90$ & 154 & 2.92 (2.25 to 3.82$)$ & $<0.001$ & 2.46 (1.87 to 3.22$)$ & $<0.001$ \\
\hline$\geq 91$ & 175 & 3.34 (2.68 to 4.16$)$ & $<0.001$ & 2.65 (2.13 to 3.30$)$ & $<0.001$ \\
\hline Any DDDs & 1683 & 2.18 (2.00 to 2.38$)$ & $<0.001$ & 2.06 (1.88 to 2.25$)$ & $<0.001$ \\
\hline
\end{tabular}

*Age, sex, physical health problems (arthritis, asthma, cancer, ischaemic heart disease, stroke, chronic obstructive pulmonary disease, diabetes, epilepsy, gastrointestinal disorders, hypertension, musculoskeletal disorders, anxiety disorders, sleep disorders, other (non-anxiety), psychiatric disorders, and prescriptions for non-study drugs. 
Table 6 | Hazard ratios (95\% confidence intervals) for age adjusted associations between defined daily doses (DDDs) of study drug and mortality before and after adjusting for other potential confounders, for exposure restricted to receipt of study drugs in first year after recruitment only and for patients with at least $\mathbf{1 2}$ months of follow-up

\begin{tabular}{|c|c|c|c|c|c|}
\hline DDDs & No of patients & $\begin{array}{l}\text { Age adjusted hazard ratio (95\% } \\
\qquad \mathrm{Cl})\end{array}$ & $P$ value & $\begin{array}{l}\text { Fully adjusted }{ }^{*} \text { hazard ratio } \\
\qquad(95 \% \mathrm{Cl})\end{array}$ & $P$ value \\
\hline \multicolumn{6}{|c|}{ All study drugs: } \\
\hline 0 & 63717 & 1.00 & - & 1.00 & - \\
\hline $1-30$ & 5142 & $1.46(1.35$ to 1.57$)$ & $<0.001$ & 1.45 (1.35 to 1.56$)$ & $<0.001$ \\
\hline $31-60$ & 1873 & 2.02 (1.82 to 2.23$)$ & $<0.001$ & 1.94 (1.76 to 2.16$)$ & $<0.001$ \\
\hline $61-90$ & 659 & 2.27 (1.94 to 2.66$)$ & $<0.001$ & 1.87 (1.59 to 2.19 ) & $<0.001$ \\
\hline$\geq 91$ & 910 & 3.14 (2.80 to 3.52 ) & $<0.001$ & 2.63 (2.34 to 2.95 ) & $<0.001$ \\
\hline Any DDDs & 8584 & 1.83 (1.73 to 1.92$)$ & $<0.001$ & 1.75 (1.65 to 1.85$)$ & $<0.001$ \\
\hline \multicolumn{6}{|c|}{ Benzodiazepines only: } \\
\hline $1-30$ & 3561 & 1.46 (1.33 to 1.59$)$ & $<0.001$ & 1.47 (1.34 to 1.61$)$ & $<0.001$ \\
\hline $31-60$ & 791 & 2.31 (2.01 to 2.65 ) & $<0.001$ & 2.07 (1.80 to 2.38 ) & $<0.001$ \\
\hline $61-90$ & 251 & 2.63 (2.09 to 3.32 ) & $<0.001$ & 2.31 (1.84 to 2.92 ) & $<0.001$ \\
\hline$\geq 91$ & 361 & 4.14 (3.53 to 4.87 ) & $<0.001$ & 3.32 (2.83 to 3.89 ) & $<0.001$ \\
\hline Any DDDs & 4964 & 1.88 (1.76 to 2.02$)$ & $<0.001$ & 1.81 (1.68 to 1.94$)$ & $<0.001$ \\
\hline \multicolumn{6}{|c|}{$Z$ drugs only: } \\
\hline $1-30$ & 655 & 1.39 (1.12 to 1.71$)$ & $<0.001$ & 1.34 (1.08 to 1.66$)$ & $<0.001$ \\
\hline $31-60$ & 603 & 2.05 (1.67 to 2.51$)$ & $<0.001$ & 2.05 (1.67 to 2.51 ) & $<0.001$ \\
\hline $61-90$ & 186 & 2.43 (1.76 to 3.36$)$ & $<0.001$ & 1.81 (1.31 to 2.51$)$ & $<0.001$ \\
\hline$\geq 91$ & 271 & 2.7 (2.15 to 3.39 ) & $<0.001$ & 2.25 (1.79 to 2.84$)$ & $<0.001$ \\
\hline Any DDDs & 1715 & 1.94 (1.72 to 2.17$)$ & $<0.001$ & 1.78 (1.58 to 2.01$)$ & $<0.001$ \\
\hline \multicolumn{6}{|c|}{ Other study drugs only: } \\
\hline $1-30$ & 785 & 1.5 (1.28 to 1.75$)$ & $<0.001$ & 1.45 (1.24 to 1.69$)$ & $<0.001$ \\
\hline $31-60$ & 310 & $1.58(1.26$ to 2.01$)$ & $<0.001$ & 1.65 (1.31 to 2.09$)$ & $<0.001$ \\
\hline $61-90$ & 113 & 1.93 (1.32 to 2.84$)$ & $<0.001$ & 1.75 (1.19 to 2.57$)$ & $<0.001$ \\
\hline$\geq 91$ & 109 & 2.36 (1.73 to 3.25$)$ & $<0.001$ & $1.9(1.39$ to 2.61$)$ & $<0.001$ \\
\hline Any DDDs & 1317 & 1.63 (1.45 to 1.82$)$ & $<0.001$ & 1.57 (1.40 to 1.76$)$ & $<0.001$ \\
\hline
\end{tabular}

*Age, sex, physical health problems (arthritis, asthma, cancer, ischaemic heart disease, stroke, chronic obstructive pulmonary disease, diabetes, epilepsy, gastrointestinal disorders, hypertension, musculoskeletal disorders, anxiety disorders, sleep disorders), other (non-anxiety) psychiatric disorders, and prescriptions for non-study drugs. 